This item was submitted to Loughborough's Research Repository by the author.

Items in Figshare are protected by copyright, with all rights reserved, unless otherwise indicated.

\title{
Permeability of hydrophilic and hydrophobic Shirasu-porous-glass (SPG) membranes to pure liquids and its microstructure
}

\section{PLEASE CITE THE PUBLISHED VERSION}

http://dx.doi.org/10.1016/j.memsci.2004.10.017

\section{PUBLISHER}

(C) Elsevier

\section{VERSION}

AM (Accepted Manuscript)

\section{LICENCE}

CC BY-NC-ND 4.0

\section{REPOSITORY RECORD}

Vladisavljevic, Goran T., Masataka Shimizu, and Tadao Nakashima. 2012. "Permeability of Hydrophilic and Hydrophobic Shirasu-porous-glass (SPG) Membranes to Pure Liquids and Its Microstructure”. figshare. https://hdl.handle.net/2134/10550. 
This item was submitted to Loughborough's Institutional Repository (https://dspace.lboro.ac.uk/) by the author and is made available under the following Creative Commons Licence conditions.

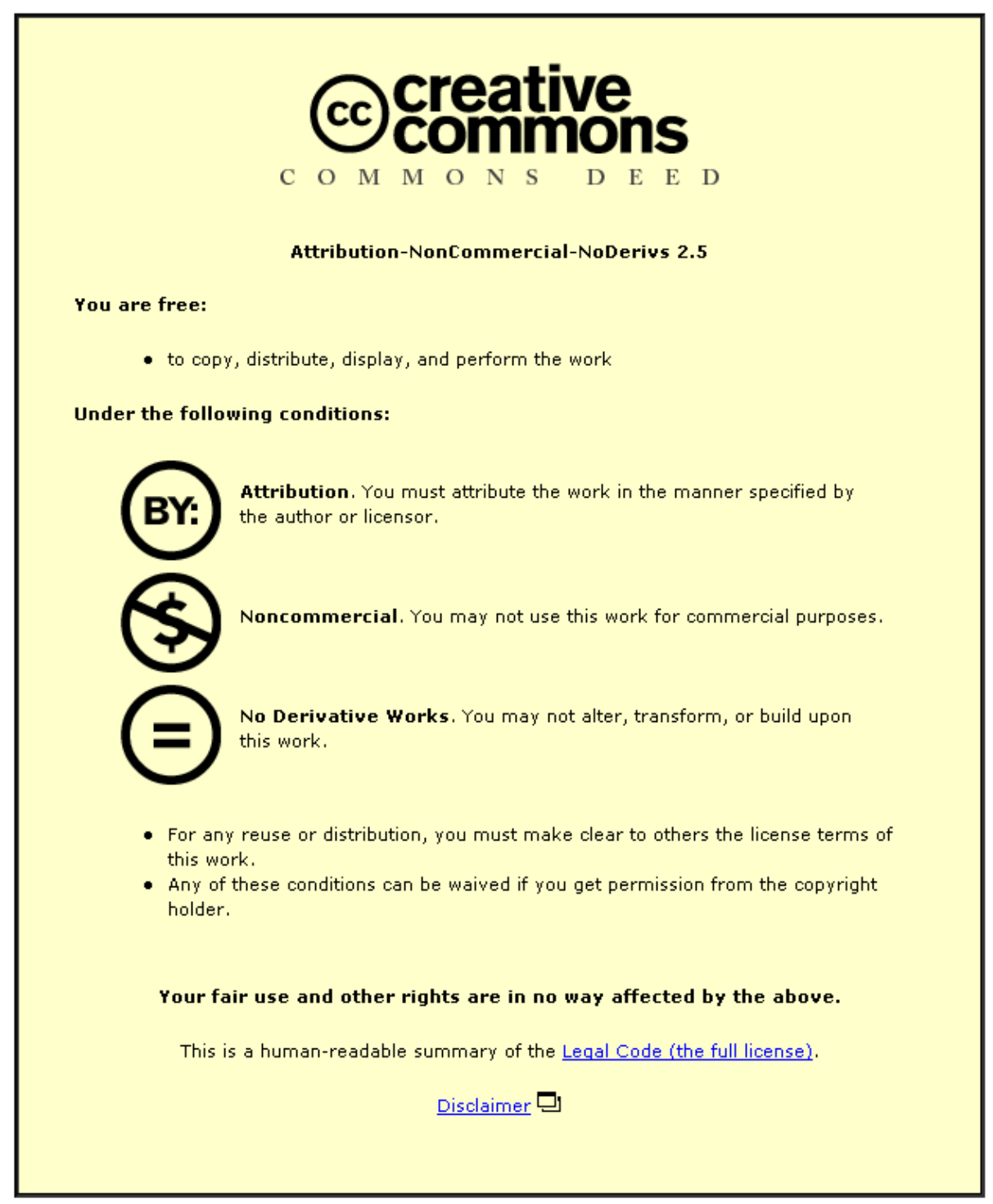

For the full text of this licence, please go to: http://creativecommons.org/licenses/by-nc-nd/2.5/ 


\section{Permeability of hydrophilic and hydrophobic Shirasu-porous-glass (SPG) membranes to pure liquids and its microstructure}

Goran T. Vladisavljević ${ }^{\mathrm{a}^{*}}$, Masataka Shimizu ${ }^{\mathrm{b}}$, Tadao Nakashima ${ }^{\mathrm{c}}$

${ }^{\mathrm{a}}$ Institute of Food Technology and Biochemistry, Faculty of Agriculture, University of Belgrade, P.O. Box 127, YU-11081 Belgrade-Zemun, Serbia, Serbia \& Montenegro.

bMiyazaki Prefectural Industrial Technology Center, 16500-2 Higashi-Kaminaka, Sadowara, Miyazaki 880-0303, Japan.

'Miyazaki Prefectural Industrial Support Foundation, 16500-2 Higashi-Kaminaka, Sadowara, Miyazaki 880-0303, Japan.

Abstract

Morphological properties of hydrophilic and hydrophobic Shirasu-porous-glass (SPG) membranes were investigated over a wide range of mean pore sizes $(0.252-20.3 \mu \mathrm{m})$ by liquid permeability measurements, scanning electron microscopy and Hg porosimetry. Hydrophobic modification of membrane surface was made by surface coating with silicone resin. The results are discussed using the non-uniform capillary bundle model of membrane permeability. The mean pore tortuosity of 1.28 was kept constant over the whole range of mean pore sizes investigated. The SEM images confirmed that the geometry of pore network was similar for all SPG membranes, irrespective of their mean pore size. The span of pore size distribution ranged from 0.28 to 0.68 and the number of pores per unit cross-sectional 
membrane area from $10^{9}$ to $10^{13} \mathrm{~m}^{-2}$. The membrane resistance was unchanged after surface treatment with silicone resin, which means that the pores were not plugged by the resin, even in the submicron range of mean pore sizes.

Keywords: Shirasu porous glass membrane; Membrane emulsification; Pore size distribution; Pore tortuosity; Membrane permeability.

\section{Introduction}

Shirasu porous glass (SPG) is a special kind of porous glass, obtained by phase separation of a primary $\mathrm{CaO}-\mathrm{Al}_{2} \mathrm{O}_{3}-\mathrm{B}_{2} \mathrm{O}_{3}-\mathrm{SiO}_{2}$ type glass, made of Shirasu (volcanic ash from the southern part of Kyushu island), calcium carbonate and boric acid [1]. Shirasu is added as a source of $\mathrm{SiO}_{2}$ and $\mathrm{Al}_{2} \mathrm{O}_{3}$, but since it is a natural material, it contains also small amounts of other components, such as $\mathrm{Na}_{2} \mathrm{O}, \mathrm{K}_{2} \mathrm{O}, \mathrm{Fe}_{2} \mathrm{O}_{3}$, etc [2]. After primary glass is formed into tube, it is subjected to heat treatment at a temperature of $650-750{ }^{\circ} \mathrm{C}$ for the periods ranging from several hours to tens of hours $[2,3]$. This treatment causes the homogeneous primary glass to transform into a heterogeneous two-phase glass consisting of $\mathrm{Al}_{2} \mathrm{O}_{3}-\mathrm{SiO}_{2}$ and CaO$\mathrm{B}_{2} \mathrm{O}_{3}$ phases. Since the $\mathrm{CaO}-\mathrm{B}_{2} \mathrm{O}_{3}$ phase is readily soluble in acid, a porous glass membrane is obtained by immersing the phase-separated glass into a dilute solution of hydrochloric acid. The mean pore size of SPG membrane can be controlled by adjusting the heat treatment conditions (time and temperature).

SPG finds many applications as a packing for HPLC columns, a carrier of enzymes and tissue cultures, an injection needle for blood transfusion and dialysis, and especially as a high-functional dispersion and separation membrane for preparing uniform droplets and micro-bubbles [3-5], microfiltration of oil-in-water (O/W) emulsions and suspensions [6-8], 
etc. The microstructure of SPG is of primary importance in any application. In membrane emulsification, the droplet size distribution of prepared emulsion depends crucially on the pore size distribution and wetting characteristics of SPG membrane used. The mean pore size determines the critical pressure under which no permeation of disperse phase is possible. In microfiltration of O/W emulsions, the pore size distribution of SPG membrane determines the rejection coefficients and the critical pressure under which the large droplets are completely retained by the membrane. Above this critical pressure the droplets pass through the membrane even if they are larger than the pore size. If SPG powder is used as a packing material for HPLC, the pore size distribution of SPG strongly affects retention time and the resolution of separation [2]. The geometries of the pore space and network play a very important role in providing high mechanical strength and high thermal resistance shock of SPG compared to the porous Vycor glass and a porous alumina of the same porosity [9].

The aim of this work was to analyze the microstructure of SPG membrane over a wide range of mean pore sizes $(0.262-20.3 \mu \mathrm{m})$ by measuring membrane permeability to pure liquids and using $\mathrm{Hg}$ intrusion porosimetry and scanning electron microscopy. The experiments have been carried out using both hydrophilic and hydrophobic SPG membranes. The SPG membrane is inherently hydrophilic due to the presence of silanol groups on the surface. However, a hydrophobic SPG membrane is indispensable in the preparation and microfiltration of water-in-oil (W/O) emulsions [10]. The special attention has been paid to the possible effects of surface treatment with silicone resin on the membrane resistance.

2. Non-uniform capillary bundle model of membrane permeability 
The permeation of wettable liquids through SPG membrane will be analyzed here by the non-uniform cylindrical capillary model. Consider a piece of SPG membrane (tube or disc) with a cross-sectional area of $\mathrm{A}_{\mathrm{m}}$, a thickness of $\delta_{\mathrm{m}}$ and a dry weight of $\mathrm{m}_{\mathrm{m}}$ containing nonuniform cylindrical pores. The number of pores per unit membrane weight in the ith range of pore sizes, the mean diameter of which is $\mathrm{d}_{\mathrm{pi}}$, can be expressed as:

$\frac{\mathrm{N}_{\mathrm{i}}}{\mathrm{m}_{\mathrm{m}}}=\frac{4 \mathrm{~V}_{\mathrm{pi}}}{\pi \mathrm{d}_{\mathrm{pi}}^{2} \mathrm{~L}_{\mathrm{i}} \mathrm{m}_{\mathrm{m}}}=\frac{4 \mathrm{~V}_{\mathrm{pi}}}{\pi \mathrm{d}_{\mathrm{pi}}^{2} \delta_{\mathrm{m}} \xi_{\mathrm{i}} \mathrm{m}_{\mathrm{m}}}$

where $V_{p i}$ is the pore volume in the $i$ th range of pore sizes, while $L_{i}$ and $\xi_{i}$ are the mean length and mean tortuosity factor of these pores. The apparent density of the membrane is given by:

$\rho_{\mathrm{a}}=\frac{\mathrm{m}_{\mathrm{m}}}{\mathrm{V}_{\mathrm{m}}}=\frac{\mathrm{m}_{\mathrm{m}}}{\mathrm{A}_{\mathrm{m}} \delta_{\mathrm{m}}}$

By substituting Eq. (2) into Eq. (1) and assuming that the mean tortuosity factor of the pores is independent on the pore size $\left(\xi_{\mathrm{i}}=\xi=\right.$ const), one obtains the expression for the number of pores per unit membrane area in the ith range of pore sizes:

$$
\frac{\mathrm{N}_{\mathrm{i}}}{\mathrm{A}_{\mathrm{m}}}=\frac{4 \rho_{\mathrm{a}} \mathrm{V}_{\mathrm{pi}}}{\pi \mathrm{d}_{\mathrm{pi}}^{2} \xi \mathrm{m}_{\mathrm{m}}}
$$

The total number of pores per unit membrane area is represented by:

$$
\frac{\mathrm{N}}{\mathrm{A}_{\mathrm{m}}}=\frac{4 \rho_{\mathrm{a}}}{\pi \xi} \sum_{\mathrm{i}=1}^{\mathrm{k}_{\mathrm{s}}} \frac{\mathrm{V}_{\mathrm{pi}} / \mathrm{m}_{\mathrm{m}}}{\mathrm{d}_{\mathrm{pi}}^{2}}
$$

where $\mathrm{k}_{\mathrm{s}}$ is the number of pore size ranges, i.e. the number of size channels provided by a pore size analyzer. $\mathrm{V}_{\mathrm{pi}} / \mathrm{m}_{\mathrm{m}}$ vs. $\mathrm{d}_{\mathrm{pi}}$ data can be easily obtained by Hg porosimetry and thus, N/A $A_{m}$ can be calculated using Eq. (4), if $\xi$ and $\rho_{a}$ are known. 
According to the Hagen-Poiseuille law, the volumetric rate of flow of a Newtonian liquid flowing through the pores with a diameter of $\mathrm{d}_{\mathrm{pi}}$ under the transmembrane pressure of $\Delta \mathrm{p}_{\mathrm{tm}}$ is given by:

$$
\mathrm{Q}_{\mathrm{i}}=\frac{\Delta \mathrm{p}_{\mathrm{tm}} \pi \mathrm{d}_{\mathrm{pi}}^{4} \mathrm{~N}_{\mathrm{i}}}{128 \eta \delta_{\mathrm{m}} \xi}
$$

where $\eta$ is the viscosity of permeating liquid. Eq. (5) holds only if the permeating liquid wets the membrane wall, but the membrane may be either hydrophilic or hydrophobic. Using Eqs. (3) and (5) one obtains the total liquid rate of flow through the membrane:

$$
\mathrm{Q}=\sum_{\mathrm{i}=1}^{\mathrm{k}_{\mathrm{s}}} \mathrm{Q}_{\mathrm{i}}=\frac{\Delta \mathrm{p}_{\mathrm{tm}} \mathrm{A}_{\mathrm{m}} \rho_{\mathrm{a}}}{32 \eta \delta_{\mathrm{m}} \xi^{2}} \sum_{\mathrm{i}=1}^{\mathrm{k}_{\mathrm{s}}}\left(\mathrm{V}_{\mathrm{pi}} / \mathrm{m}_{\mathrm{m}}\right) \mathrm{d}_{\mathrm{pi}}^{2}
$$

The transmembrane flux of permeating liquid can be expressed as follows:

$$
\mathrm{J}_{\mathrm{w}}=\frac{\Delta \mathrm{p}_{\mathrm{tm}}}{\eta \mathrm{R}_{\mathrm{m}}}=\frac{\mathrm{Q}}{\mathrm{A}_{\mathrm{m}}}=\frac{\Delta \mathrm{p}_{\mathrm{tm}} \rho_{\mathrm{a}}}{32 \eta \delta_{\mathrm{m}} \xi^{2}} \sum_{\mathrm{i}=1}^{\mathrm{k}_{\mathrm{s}}}\left(\mathrm{V}_{\mathrm{pi}} / \mathrm{m}_{\mathrm{m}}\right) \mathrm{d}_{\mathrm{pi}}^{2}
$$

from which the hydrodynamic membrane resistance is given by:

$$
\mathrm{R}_{\mathrm{m}}=\frac{32 \delta_{\mathrm{m}} \xi^{2}}{\rho_{\mathrm{a}} \sum_{\mathrm{i}=1}^{\mathrm{k}_{\mathrm{s}}}\left(\mathrm{V}_{\mathrm{pi}} / \mathrm{m}_{\mathrm{m}}\right) \mathrm{d}_{\mathrm{pi}}^{2}}
$$

However:

$$
\sum_{\mathrm{i}=1}^{\mathrm{k}_{\mathrm{s}}}\left(\mathrm{V}_{\mathrm{pi}} / \mathrm{m}_{\mathrm{m}}\right) \mathrm{d}_{\mathrm{pi}}^{2}=\frac{\varepsilon}{\rho_{\mathrm{a}}} \sum_{\mathrm{i}=1}^{\mathrm{k}_{\mathrm{s}}} \mathrm{r}_{\mathrm{i}} \mathrm{d}_{\mathrm{pi}}^{2}=\frac{\varepsilon \mathrm{d}_{\mathrm{p}}^{2}}{\rho_{\mathrm{a}}}
$$

where $\varepsilon$ is the porosity of membrane wall, $\mathrm{r}_{\mathrm{i}}$ is the volume fraction of the pores in the $i$ th range of pore sizes, i.e. the volume of the pores in the $i$ th range divided by the total pore volume, and $\mathrm{d}_{\mathrm{p}}$ is the volume-weighted mean pore diameter given by:

$$
d_{p}=\sqrt{\sum_{i=1}^{k_{s}} r_{i} d_{p i}^{2}}=\sqrt{\left(\rho_{a} / \varepsilon\right) \sum_{i=1}^{k_{s}}\left(V_{p i} / m_{m}\right) d_{p i}^{2}}=\sqrt{4 \varepsilon A_{m} /(\pi \xi N)}
$$


Eqs. (8) and (4) can be simplified using Eq. (9) to the well-known equations derived using the uniform capillary bundle model [11]:

$$
\begin{aligned}
& \mathrm{R}_{\mathrm{m}}=\frac{32 \delta_{\mathrm{m}} \xi^{2}}{\varepsilon \mathrm{d}_{\mathrm{p}}^{2}} \\
& \frac{\mathrm{N}}{\mathrm{A}_{\mathrm{m}}}=\frac{4 \varepsilon}{\pi \xi \mathrm{d}_{\mathrm{p}}^{2}}
\end{aligned}
$$

The hydrodynamic permeability of membrane is given by:

$$
\mathrm{P}=\frac{1}{\mathrm{R}_{\mathrm{m}}} \frac{\delta_{\mathrm{m}}}{\eta}=\frac{\varepsilon \mathrm{d}_{\mathrm{p}}^{2}}{32 \eta \xi^{2}}
$$

It should be noted that the membrane resistance, $\mathrm{R}_{\mathrm{m}}$, is independent on the viscosity of the permeating liquid, $\eta$ (Eq. 11), but depends on the membrane thickness, $\delta_{\mathrm{m}}$. On the other hand, the membrane permeability, $\mathrm{P}$, is inversely proportional to $\eta$, but it is unaffected by the membrane thickness.

\section{Experimental}

\subsection{Membranes and membrane modules}

The permeability experiments have been carried out using 9 different SPG membrane tubes obtained from SPG Technology Co., Sadowara, Japan with an inner diameter of 7.9$8.6 \mathrm{~mm}$ and a thickness of 655-895 $\mu \mathrm{m}$ (Tab. 1). The effective membrane length was 57 or $109 \mathrm{~mm}$, depending on the module size. The membrane length and thickness was determined using a Mitutoyo model CD-20C digimatic micrometer. The pore size distribution and wall porosity of the membranes was measured using a Shimadzu model 9320 mercury porosimeter. The volume-weighted mean pore diameter was deduced from the experimental $V_{p i} / m_{m}$ vs. $d_{p i}$ data by using Eq. (10). The relative span of pore size distribution was calculated from the experimental data using the equation: $\operatorname{span}=\left(\mathrm{d}_{90^{-}}\right.$ 
$\left.\mathrm{d}_{10}\right) / \mathrm{d}_{50}$, where $\mathrm{d}_{\mathrm{X} 0}$ is the pore diameter corresponding to $\mathrm{X} 0$ vol. \% on a cumulative pore volume curve. The pore structure was observed by a field-emission type S-800M Hitachi scanning electron microscope. The membrane samples were sputter-coated with platinumpalladium alloy (8:2) using a Hitachi E-1030 ion sputter coater.

In order to investigate the influence of wall wettability on permeation behavior, SPG membranes were coated with silicone resin to render its surface hydrophobic. This treatment involved the immersion of membrane in a commercial silicone resin solution (KP-18C, Shin-Etsu Chem. Ind. Co., Ltd, diluted with distilled water in the ratio of 1:100) at room temperature for $24 \mathrm{~h}$, followed by drying in an oven at $100^{\circ}-120^{\circ} \mathrm{C}$ for several hours [12]. After immersion, the air bubbles were removed from the interior of the pores by ultrasonication for 15 min. The hydrophilic nature of SPG membrane can be restored again by heating the hydrophobic membrane at $500{ }^{\circ} \mathrm{C}$ for $30 \mathrm{~min}[12]$.

\subsection{Experimental set-up and procedure}

The experimental set-up used for membrane permeability measurements is shown in Fig. 1. The permeating liquid (distilled water for hydrophilic membrane and $99.5 \%$ ethanol for hydrophobic membrane) was placed in a pressure vessel and introduced at the shell side of the module by compressed air. The tube side of the module was open to the atmosphere. The permeate weight was measured by a Mettler Toledo model PR 5002 precision balance with a readability of $0.01 \mathrm{~g}$, placed below the permeate outlet. The balance was interfaced to a PC computer to collect time and mass data using a WIN for METTLER version 5.02 data acquisition software. The shortest time between two consecutive measurements was $1 \mathrm{~s}$. The transmembrane pressure was measured using Copal Electronics pressure gauges with an accuracy of $\pm 1 \mathrm{kPa}$ (PG-200) and $\pm 0.1 \mathrm{kPa}$ (PG-30). For high liquid flow rates, e.g. when 
the mean pore size was $5.4 \mu \mathrm{m}$ or larger, due to a significant pressure drop in a line connecting the pressure vessel and the module, the transmembrane pressure was measured using the pressure gauge attached directly to the module shell (G2 in Fig. 1). For relatively small liquid flow rates, the transmembrane pressure was measured using either G1 or G2 pressure gauge. All experiments were performed at $298 \mathrm{~K}$. The density of permeating liquids at this temperature was 997 and $790 \mathrm{~kg} / \mathrm{m}^{3}$ for water and ethanol, respectively. The dynamic viscosity at $298 \mathrm{~K}$ was 0.90 and $1.12 \mathrm{mPa} \cdot \mathrm{s}$ for water and ethanol, respectively.

\section{Results and discussion}

\subsection{Pore structure of SPG membranes}

Figures 2 and 3 show the scanning electron micrographs of two SPG membranes largely differing in mean pore size, but with virtually the same porosity (56.65 $\pm 0.05 \%$ ). It is clear that the pore structure remained unchanged when the mean pore size increased. In both cases, the membrane contains cylindrical tortuous pores forming a threedimensional interconnected network. All of the pore cross-sections are not circular, because the pores do not always intersect with the external surfaces at a right angle, and the pore joints also appear in the photographs. A non-circular cross section of the pores plays an important role in providing a spontaneous detachment of disperse phase from the pore outlets in membrane emulsification under low shear stress conditions [13].

Fig. 4 is the SEM picture of the same membrane as in Fig. 2, but after coating with silicone resin. Although the presence of coated layer is visible in the micrographs, it can be seen that the pores are not blocked by the resin.

Fig. 5. shows the pore size distribution of SPG membranes given in Figs. 2 and 3. Obviously, the pore size distribution curves of the two membranes are of the similar shape 
and width, in spite of the fact that their mean pore sizes largely differ. The pore size distribution of all SPG membranes used in this study is shown in Fig. 6. The span values were in the range of $0.29-0.68$ (Tab. 1), which is comparable with the typical spans of the particle size distribution of the emulsions prepared using SPG membranes $[4,14,15]$. The least uniform pores $(\operatorname{span}=0.68)$ were obtained at the largest mean pore size of $20.3 \mu \mathrm{m}$.

\subsection{Permeability of SPG membranes to pure liquids}

Typical $V_{w}$ vs. $t$ plot for the permeation of water through a hydrophilic SPG membrane is shown in Fig. 7. The same type of behavior was found for the permeation of ethanol through a hydrophobic SPG membrane. The pure water flux was determined from the slope of the $\mathrm{V}_{\mathrm{w}}$ vs. $\mathrm{t}$ lines using the equation: $\mathrm{J}_{\mathrm{w}}=\left(\partial \mathrm{V}_{\mathrm{w}} / \partial \mathrm{t}\right) / \mathrm{A}_{\mathrm{m}}$, where $\partial \mathrm{V}_{\mathrm{w}} / \partial \mathrm{t}$ is the slope of the $\mathrm{V}_{\mathrm{w}} \mathrm{vs}$. t lines. The pure water flux through hydrophilic SPG membrane linearly increased with increasing the transmembrane pressure (Fig. 8), which is an indication of laminar flow regime in the pores. Each data point in Fig. 8 represents an arithmetic mean value of three repeated experiments. The coefficient of variation of $\mathrm{J}_{\mathrm{w}}$ in repeated experiments was less than $4 \%$. As expected from the Hagen-Poiseuille law, the water flux was higher for the larger mean pore size. If the SPG membrane was hydrophobic and initially dry (dotted lines in Fig. 8), the water flux was not observed below a critical pressure. After reaching the critical pressure, the water flux sharply increases and approaches a straight line representing $\mathrm{J}_{\mathrm{w}}-\Delta \mathrm{p}_{\mathrm{tm}}$ dependency for the same hydrophilic membrane.

For driving pressures below the critical pressure, the water flux is zero and the governing equation is the Laplace equation for the capillary pressure. For driving pressures much larger than the capillary pressure, the same hydrodynamic equations holds for both a hydrophilic and hydrophobic membrane, and no differences in water fluxes can be observed. 
For intermediary pressures, some proportion of the pores are still dry (non-active), the remaining being filled with water (active) and the water flux is smaller than for the same hydrophilic membrane. With increasing the pressure above the critical pressure, the more and more pores become active and the difference in water fluxes for hydrophilic and hydrophobic membranes is smaller and smaller. The ratio of water flux for a hydrophobic membrane to that for a hydrophilic membrane should be equal to the proportion of active pores. The critical pressure was inversely proportional to the mean pore size (e.g. 55 and 30 $\mathrm{kPa}$ for $\mathrm{d}_{\mathrm{p}}$ value of 2.0 and $3.8 \mu \mathrm{m}$, respectively), which was in agreement with the Laplace equation. If a dry hydrophobic membrane is immersed into water the pores remain dry and the critical pressure will not be affected. Therefore, the critical pressure is not related to the transition from a dry to a wet membrane. However, if a wet hydrophobic membrane is subjected to the pressures well above the critical pressure and if the pressure is then released, the membrane becomes activated. The critical pressure of such activated wet hydrophobic membrane is smaller, depending on the pressure applied during pore activation.

The slope of the $\mathrm{J}_{\mathrm{w}}$ vs. $\Delta \mathrm{p}_{\mathrm{tm}}$ lines in Fig. 8 allows determination of the hydrodynamic membrane resistance using the equation: $R_{m}=\left(1 / \eta_{w}\right)\left(\partial J_{w} / \partial \Delta p_{t m}\right)^{-1}$. Alternatively, $R_{m}$ can be estimated from the intercept of the $\mathrm{J}_{\mathrm{w}}$ vs. $\Delta \mathrm{p}_{\mathrm{tm}}$ lines in logarithmic coordinates (Fig. 9); the higher this intercept, the smaller the membrane resistance. The slope of all lines in this plot should be equal to unity. The $\mathrm{R}_{\mathrm{m}}$ values determined from the plots given in Figs. 8 and 9 were in an excellent agreement.

The linear fit of $\log \left(\mathrm{R}_{\mathrm{m}}\right)$ vs. $\log \left(\mathrm{d}_{\mathrm{p}}\right)$ data (Fig. 10) gave the following equation for both hydrophobic and hydrophilic SPG membranes:

$$
\mathrm{R}_{\mathrm{m}}=0.0691 \mathrm{~d}_{\mathrm{p}}^{-1.985}
$$

where $R_{m}$ and $d_{p}$ are in $m^{-1}$ and $m$, respectively. Therefore, the membrane resistance did not 
change after surface treatment with the silicone resin, i.e. no pore plugging by the resin occurred at the given conditions, even in the submicron range of mean pore sizes. The exponent on $d_{p}$ of -1.985 is very close to -2 , predicted by Eq. (11) for laminar flow through unconnected capillaries. Therefore, liquid permeation through any wettable SPG membrane (hydrophilic or hydrophobic) obeys the Hagen-Poiseuille law over the whole range of mean pore sizes. This means that the effects of flow divergence and confluence on liquid permeation are negligibly small. The linear fit of data in Fig. 10 using a fixed slope of -2 gave the equation:

$$
\mathrm{R}_{\mathrm{m}}=0.0704 \mathrm{~d}_{\mathrm{p}}^{-2}
$$

In Fig. 11, the permeability of SPG membrane to different wettable liquids (water for hydrophilic membrane and ethanol for hydrophobic membrane) is plotted against the mean pore size. The membrane permeability was calculated using the equation: $\mathrm{P}=\delta_{\mathrm{m}}\left(\partial \mathrm{J} / \partial \Delta \mathrm{p}_{\mathrm{tm}}\right)$, derived from Eqs. (7) and (13). As shown in Fig. 11, the permeability of hydrophobic SPG membranes to ethanol is smaller than the permeability of hydrophilic SPG membranes to pure water. It is due to the fact that water has a smaller viscosity than ethanol. The slope of the P vs. $d_{p}$ line of 1.98 for hydrophilic membrane (solid line) and 1.97 for hydrophobic membrane (dotted line) is similar to a theoretical value of 2, predicted by Eq. (13).

In Fig. 12, the product of membrane permeability and liquid viscosity (the modified permeability), $\mathrm{P \eta}$, which is independent on the physical properties of the permeating liquid or membrane thickness, was plotted against $\mathrm{d}_{\mathrm{p}}{ }^{2} \varepsilon$ using logarithmic coordinates. It is seen that the data for hydrophilic and hydrophobic membranes can be correlated by a single line (correlation coefficient $=0.99975$ ) with a slope of unity, whose equation is:

$\mathrm{P} \eta=0.0191 \mathrm{~d}_{\mathrm{p}}^{2} \varepsilon$

The modified membrane resistance, $\mathrm{R}_{\mathrm{m}} / \delta_{\mathrm{m}}$, is obtained from Eqs. (16) and (13): 
$\frac{\mathrm{R}_{\mathrm{m}}}{\delta_{\mathrm{m}}}=\frac{52.4}{\mathrm{~d}_{\mathrm{p}}^{2} \varepsilon}$

Eq. (16) and (17) suggest that the morphology of membrane pores is remained constant over the wide interval of mean pore sizes, ranging from a submicron range to over $20 \mu \mathrm{m}$. This means that in spite of quite different conditions of phase separation during porous glass preparation, the prepared SPG membranes are characterized by the similar geometry of the pore space.

Using Eq. (13) and (16), the mean tortuosity factor $\xi$ of the pores can be calculated as follows:

$\xi=\frac{1}{\sqrt{32 \times 0.0191}}=1.28$

The calculated $\xi$ value of 1.28 is close to 1.32 , found earlier by Nakashima and Shimizu [2] for SPG membranes in the range of mean pore sizes of $0.39-8.0 \mu \mathrm{m}$. It is also similar to 1.25 found by Vladisavljević et al. [15] for hydrophilic SPG membranes in the range of mean pore sizes of 0.4-6.6 $\mu \mathrm{m}$. As a comparison, the mean pore tortuosity of flat and hollow fiber polyproplylene MF membranes ranges between 1.9 and 2.8 [16, 17].

In Fig. 13, the number of pores per unit membrane area, N/A $A_{m}$ was plotted against the mean pore size in logarithmic coordinates. The $\mathrm{N} / \mathrm{A}_{\mathrm{m}}$ values for each membrane were calculated from Eq. (12). The $\varepsilon$ values were taken from Tab. 1 and the $\xi$ values were calculated for each membrane from the experimental $R_{m}$ and $\delta_{m}$ values, using Eq. (11). The number of pores per unit membrane area was inversely proportional to the square of the mean pore size, with the following equation:

$$
\mathrm{N} / \mathrm{A}_{\mathrm{m}}=0.56 \mathrm{~d}_{\mathrm{p}}^{-2}
$$


where $N / A_{m}$ and $d_{p}$ are in $m^{-2}$ and $m$, respectively. Eq. (19) enables to predict N/A for any SPG membrane, irrespective of their mean pore size or surface affinity.

\section{Conclusions}

The non-uniform capillary bundle model of membrane permeability developed here was simplified to the conventional uniform capillary bundle model by adopting the volumeweighted mean droplet diameter (Eq. 10) as a characteristic mean pore size. This model was applicable to both hydrophilic and hydrophobic SPG membrane over the whole range of mean pore sizes investigated, on the condition that the membrane wall was wetted with the permeating liquid. The morphological characteristics of SPG membrane were remarkably constant and independent on the mean pore size. The membrane resistance was unchanged after surface coating with silicone resin. The hydrophobic nature of SPG membrane treated with silicone resin was confirmed by the existence of a critical pressure, under which the permeation of pure water was not possible. The obtained results are important for modeling the performances of SPG membrane emulsification.

\section{List of Symbols}
$\mathrm{A}_{\mathrm{m}} \quad$ cross-sectional area of membrane, $\mathrm{m}^{2}$
$\mathrm{A}_{\mathrm{p}} \quad$ area of pore walls, $\mathrm{m}^{2}$
$\mathrm{d}_{\mathrm{p}} \quad$ volume-weighted mean pore diameter, $\mathrm{m}$
$\mathrm{J} \quad$ transmembrane flux of permeating liquid, $\mathrm{m} \mathrm{s}^{-1}$
$\mathrm{k}_{\mathrm{s}} \quad$ number of pore size ranges, -
L mean length of pores, $\mathrm{m}$
$\mathrm{m}_{\mathrm{m}} \quad$ dry weight of membrane, $\mathrm{kg}$ 
$\mathrm{N}$ number of pores, -

$\mathrm{P} \quad$ hydrodynamic permeability of membrane, $\mathrm{m}^{2} \mathrm{~Pa}^{-1} \mathrm{~s}^{-1}$

$\Delta \mathrm{p}_{\mathrm{tm}} \quad$ transmembrane pressure, $\mathrm{Pa}$

Q volumetric rate of flow of permeating liquid, $\mathrm{m}^{3} \mathrm{~s}^{-1}$

$\mathrm{R}_{\mathrm{m}} \quad$ hydrodynamic resistance of membrane, $\mathrm{m}^{-1}$

R coefficient of correlation, -

$r_{i} \quad$ volume fraction of pores in ith range of pore sizes, -

span relative span factor of pore size distribution, -

$\mathrm{t} \quad$ time, $\mathrm{s}$

$\mathrm{V} \quad$ volume of permeating liquid, $\mathrm{m}^{3}$

$\mathrm{V}_{\mathrm{m}} \quad$ total volume of membrane, $\mathrm{m}^{3}$

$\mathrm{V}_{\mathrm{p}} \quad$ total pore volume, $\mathrm{m}^{3}$

$\delta_{\mathrm{m}} \quad$ thickness of membrane wall, $\mathrm{m}$

$\varepsilon \quad$ porosity of membrane wall $\left(\mathrm{V}_{\mathrm{p}} / \mathrm{V}_{\mathrm{m}}\right)$, -

$\eta \quad$ viscosity of permeating liquid, Pa s

$\rho \quad$ true density of membrane, $\mathrm{kg} \mathrm{m}^{-3}$

$\rho_{\mathrm{a}} \quad$ apparent density of membrane, $\mathrm{kg} \mathrm{m}^{-3}$

$\xi \quad$ mean tortuosity factor of pores, -

Subscripts

i refers to ith range of pore sizes

w refers to water

Acknowledgement. 
The authors wish to thank the Japan Society for the Promotion of Science (JSPS), Tokyo, Japan for the financial support of this work. 


\section{References}

[1] T. Nakashima and M. Shimizu, Porous glass from calcium alumino boro-silicate glass, Ceramics Japan, 21 (1986) 408.

[2] T. Nakashima, Porous glass material and its recent applications, Society for the Application of SPG Technology, Miyazaki, Japan, 1989, p. 10.

[3] T. Nakashima, M. Shimizu and M. Kukizaki, Particle control of emulsion by membrane emulsification and its applications, Adv. Drug Deliv. Rev., 45 (2000) 47.

[4] G.T. Vladisavljević and H. Schubert, Influence of process parameters on droplet size distribution in SPG membrane emulsification and stability of prepared emulsion droplets, J. Membr. Sci., 225 (2003) 15.

[5] K. Kandori, Applications of microporous glass membranes: membrane emulsification, in A.G. Gaonkar (Ed.), Food Processing: Recent Developments, Elsevier Science B.V., Amsterdam, 1995, p. 113.

[6] T. Nakashima and M. Shimizu, Microfiltration of emulsion by porous glass membrane, Kagaku Kogaku Ronbunshu, 15 (1989) 645.

[7] T. Nakashima and M. Shimizu, Effect of oil concentration in microfiltration by porous glass membrane, Kagaku Kogaku Ronbunshu, 20 (1994) 468.

[8] M. Kukizaki, T. Nakashima and M. Shimizu, Preparation of new asymmetric type of porous glass and effect of its structure on microfiltration, Membrane, 27 (2002) 324.

[9] T. Nakashima, M. Shimizu and M. Kukizaki, Mechanical strength and thermal resistance of porous glass, J. Cer. Soc. Japan Int., 100 (1992) 1389.

[10] M. Shimizu, T. Nakashima and M. Kukizaki, Preparation of W/O emulsion by membrane emulsification and optimum conditions for its monodispersion, Kagaku Kogaku Ronbunshu, 28 (2002) 310. 
[11] T. Nakashima and M. Shimizu, Liquid permeability of porous glass membrane and its microstructure, J. Cer. Soc. Japan Int., 101 (1993) 516.

[12] T. Nakashima, M. Shimizu and M. Kukizaki, Membrane Emulsification Operation Manual, $1^{\text {st }}$ Edition, Industrial Research Institute of Miyazaki Prefecture, Japan, 1991.

[13] I. Kobayashi, M. Nakajima, K. Chun, Y. Kikuchi and H. Fujita, Silicon array of elongated through-holes for monodisperse emulsion droplets, AIChE J., 48 (2002) 1639.

[14] G.T. Vladisavljević, U. Lambrich, M. Nakajima and H. Schubert, Production of O/W emulsions using SPG membranes, ceramic $\alpha-\mathrm{Al}_{2} \mathrm{O}_{3}$ membranes, microfluidizer and a microchannel plate - a comparative study, Colloid. Surface. A, 232 (2004) 199.

[15] T. Nakashima, M. Shimizu and M. Kukizaki, Effect of surfactant on production of monodispersed $\mathrm{O} / \mathrm{W}$ emulsion in membrane emulsification, Kagaku Kogaku Ronbunshu, 19 (1993) 991.

[16] A. Kiani, R.R. Bhave and K.K. Sirkar, Solvent extraction with immobilized interfaces in a microporous hydrophobic membrane, J. Membr. Sci., 20 (1984) 125.

[17] R. Prasad and K. Sirkar, Dispersion-free solvent extraction with microporous hollowfiber modules, AIChE J., 34 (1988) 177. 


\section{TABLES}

Table 1. The characteristics of SPG membranes used in this work.

\begin{tabular}{ccccccccc}
\hline \hline No. & $\mathrm{d}_{\mathrm{p}}(\mu \mathrm{m})$ & $\begin{array}{c}\text { Span of } \\
\text { PSD }(/)\end{array}$ & $\varepsilon(\%)$ & $\begin{array}{c}\rho_{\mathrm{a}} \\
\left(\mathrm{kg} / \mathrm{dm}^{3}\right)\end{array}$ & $\begin{array}{c}\rho \\
\left(\mathrm{kg} / \mathrm{dm}^{3}\right)\end{array}$ & $\begin{array}{c}\mathrm{V}_{\mathrm{p}} / \mathrm{m}_{\mathrm{m}} \\
\left(\mathrm{dm}^{3} / \mathrm{kg}\right)\end{array}$ & $\begin{array}{c}\mathrm{A}_{\mathrm{p}} / \mathrm{m}_{\mathrm{m}} \\
\left(\mathrm{dm}^{2} / \mathrm{g}\right)\end{array}$ & $\delta_{\mathrm{m}}(\mu \mathrm{m})$ \\
\hline \hline 1 & 0.262 & 0.51 & 56.7 & 1.08 & 2.28 & 0.527 & 95.6 & 860 \\
2 & 0.525 & 0.46 & 56.2 & 1.04 & 2.37 & 0.541 & 46.7 & 845 \\
3 & 1.96 & 0.29 & 55.3 & 1.08 & 2.43 & 0.510 & 11.3 & 860 \\
4 & 3.76 & 0.49 & 57.4 & 0.971 & 2.28 & 0.591 & 8.67 & 655 \\
5 & 5.39 & 0.60 & 58.1 & 0.954 & 2.28 & 0.609 & 6.21 & 895 \\
6 & 7.63 & 0.44 & 50.4 & 0.992 & 2.00 & 0.508 & 2.78 & 710 \\
7 & 10.7 & 0.55 & 55.2 & 0.980 & 2.19 & 0.563 & 3.35 & 795 \\
8 & 14.8 & 0.54 & 56.6 & 1.00 & 2.31 & 0.564 & 2.76 & 750 \\
9 & 20.3 & 0.68 & 54.3 & 0.971 & 2.13 & 0.560 & 1.46 & 790 \\
\hline \hline
\end{tabular}




\section{FIGURE CAPTIONS}

Figure 1. Experimental set-up for measurements of membrane permeability used in this study.

Figure 2. Scanning electron micrograph of the hydrophilic SPG membrane with $d_{p}=$ $0.262 \mu \mathrm{m}$ (No. 1 in Tab. 1).

Figure 3. Scanning electron micrograph of the hydrophilic SPG membrane with $d_{p}=$ $14.8 \mu \mathrm{m}$ (No. 8 in Tab. 1).

Figure 4. Scanning electron micrograph of the hydrophobic SPG membrane with $d_{p}=$ $0.262 \mu \mathrm{m}$ (No. 1 in Tab. 1).

Figure 5. Pore size distribution on a frequency basis of SPG membranes shown in Fig. 2 and 3.

Figure 6. Pore size distribution on a cumulative basis of all SPG membranes used in this work.

Figure 7. Volume versus time data for the permeation of pure water through a hydrophilic SPG membrane with $\mathrm{d}_{\mathrm{p}}=0.262 \mu \mathrm{m}$. 
Figure 8. Pure water flux through hydrophilic SPG membranes as a function of transmembrane pressure (solid lines). Pure water flux through hydrophobic SPG membranes is represented by the dashed lines.

Figure 9. Pure water flux versus transmembrane pressure for hydrophilic SPG membranes.

Figure 10. Hydrodynamic resistance of hydrophilic and hydrophobic SPG membrane as a function of mean pore size.

Figure 11. Hydrodynamic permeability of hydrophilic SPG membrane to pure water (solid line) and of hydrophobic SPG membrane to $99.5 \%$ ethanol (dashed line).

Figure 12. Relationship between $\mathrm{P} \eta$ and $\mathrm{d}_{\mathrm{p}}^{2} \varepsilon$ for hydrophilic and hydrophobic SPG membranes.

Figure 13. Number of pores per unit cross-sectional area of membrane as a function of mean pore size for hydrophilic and hydrophobic SPG membranes. 


\section{FIGURES}

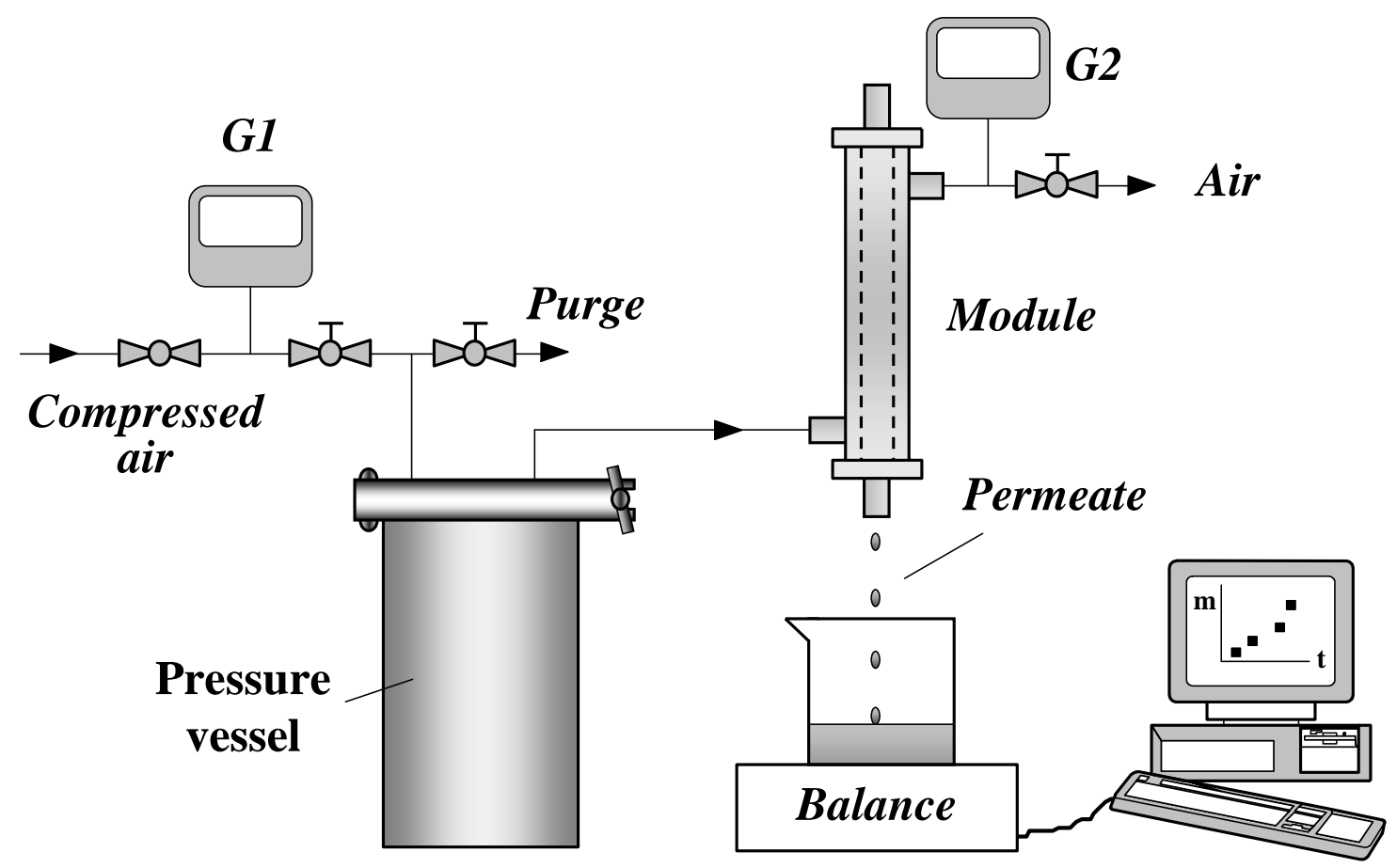

Fig. 1, Vladisavljević et al. 

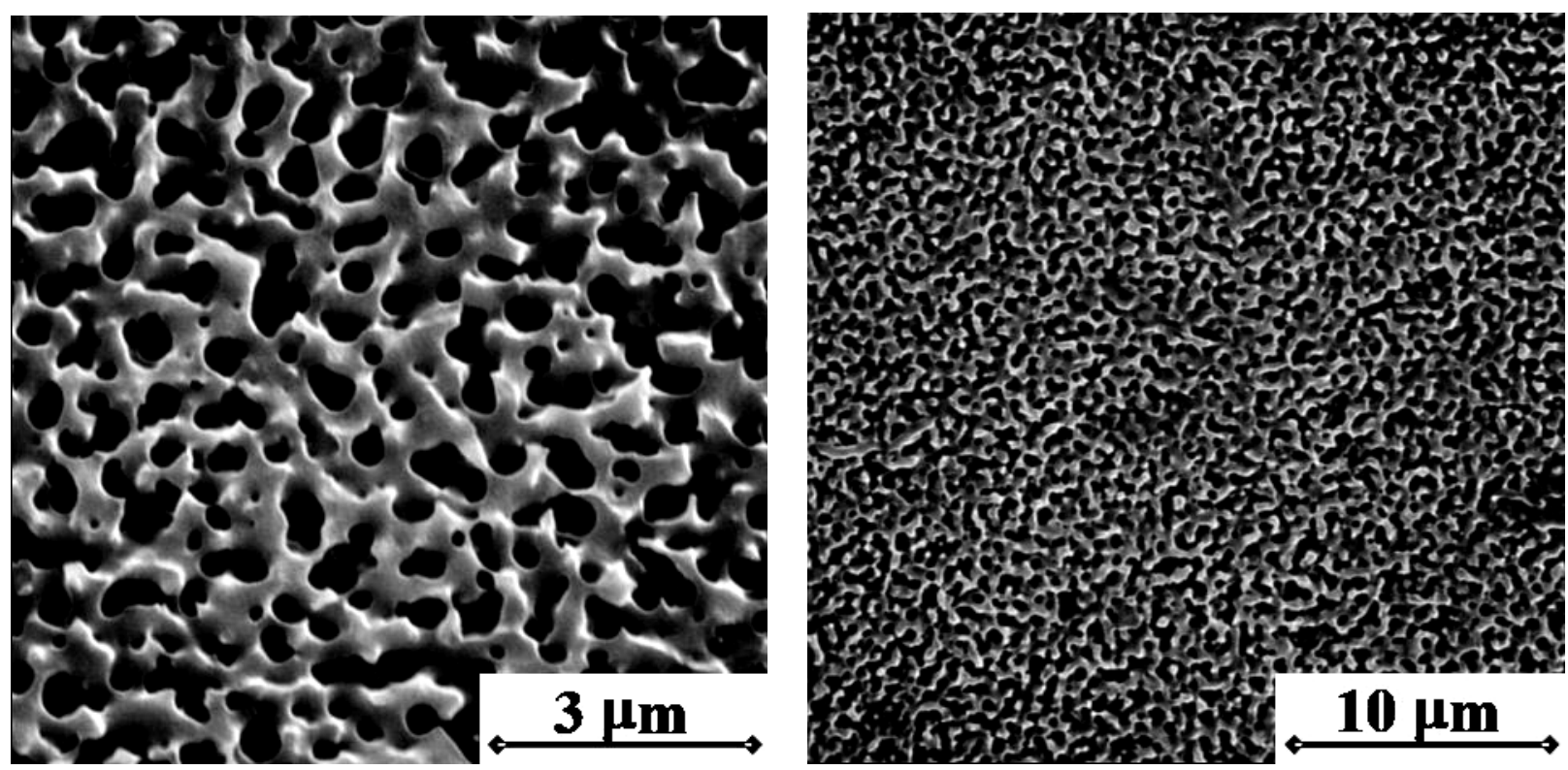

Fig. 2, Vladisavljević et al. 

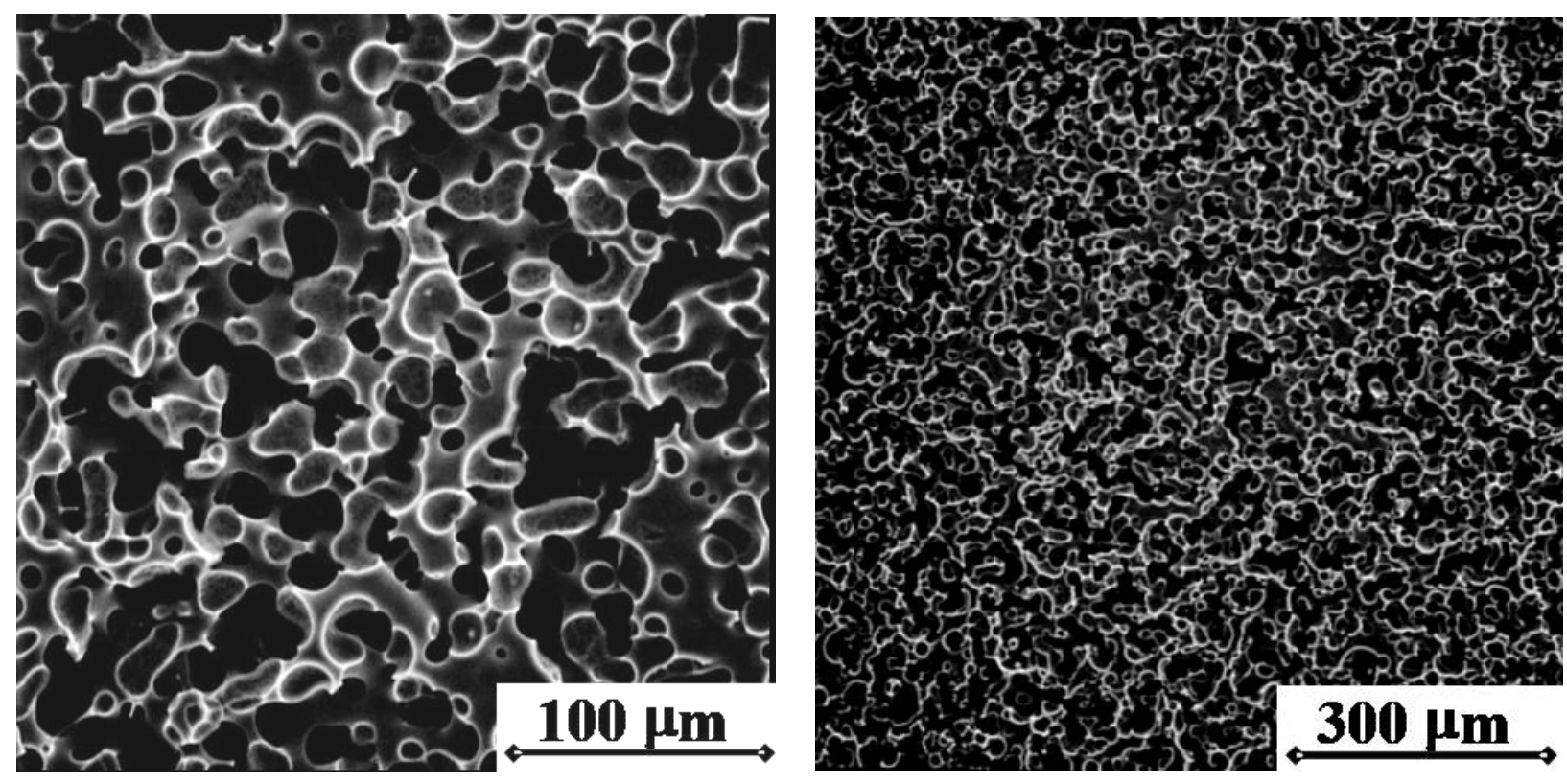

Fig. 3, Vladisavljević et al. 

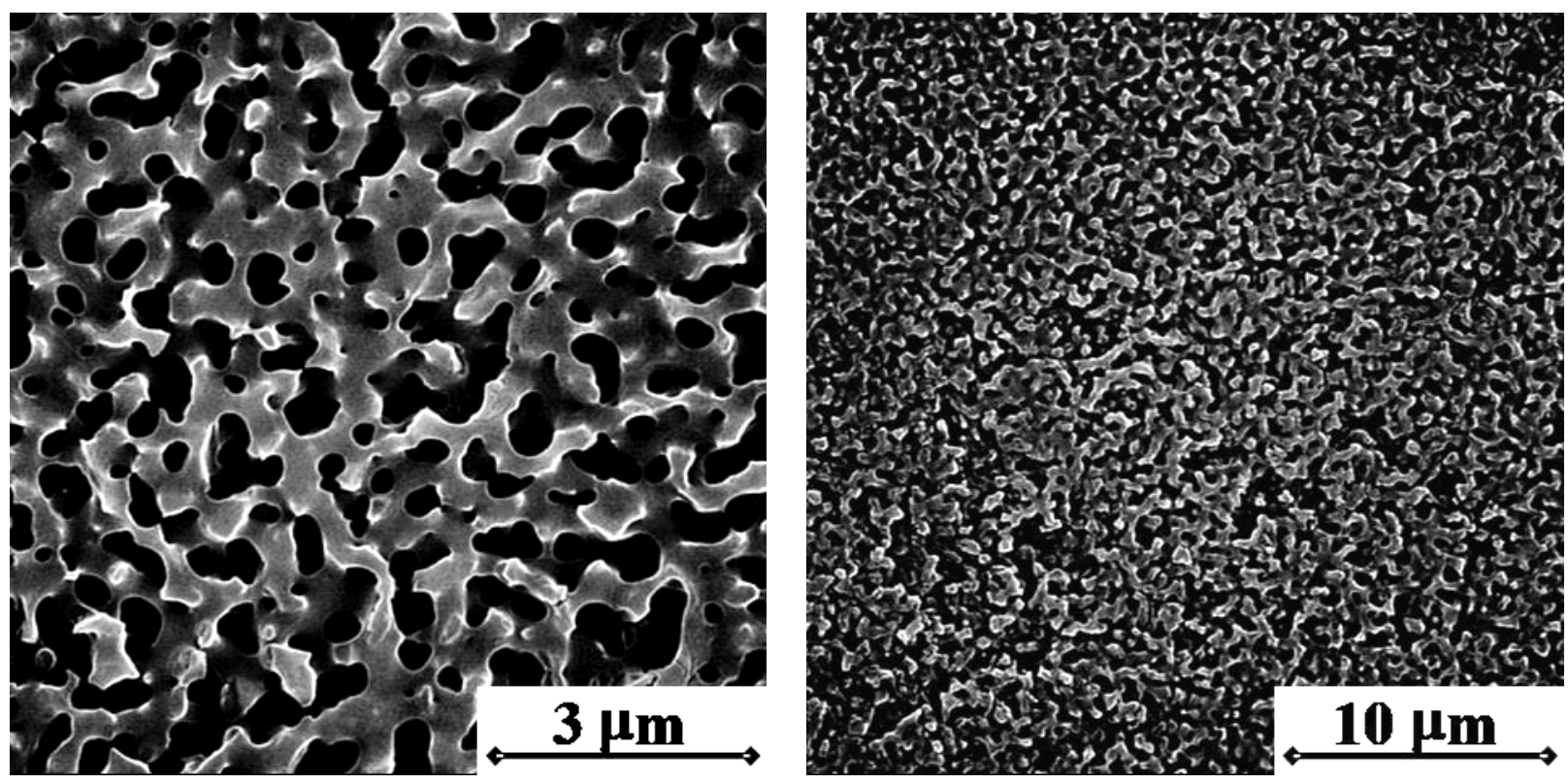

Fig. 4, Vladisavljević et al. 


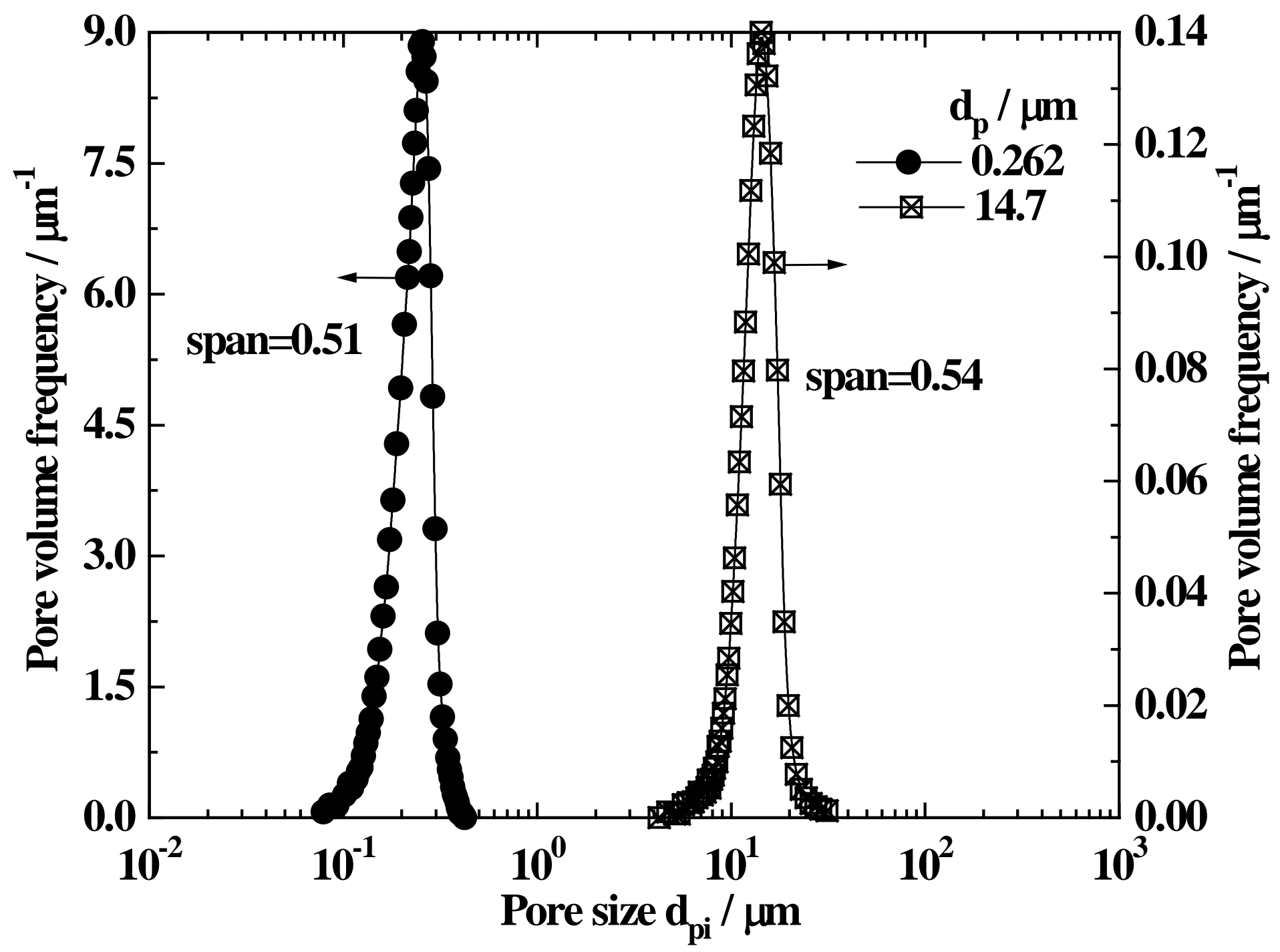

Fig. 5, Vladisavljević et al. 


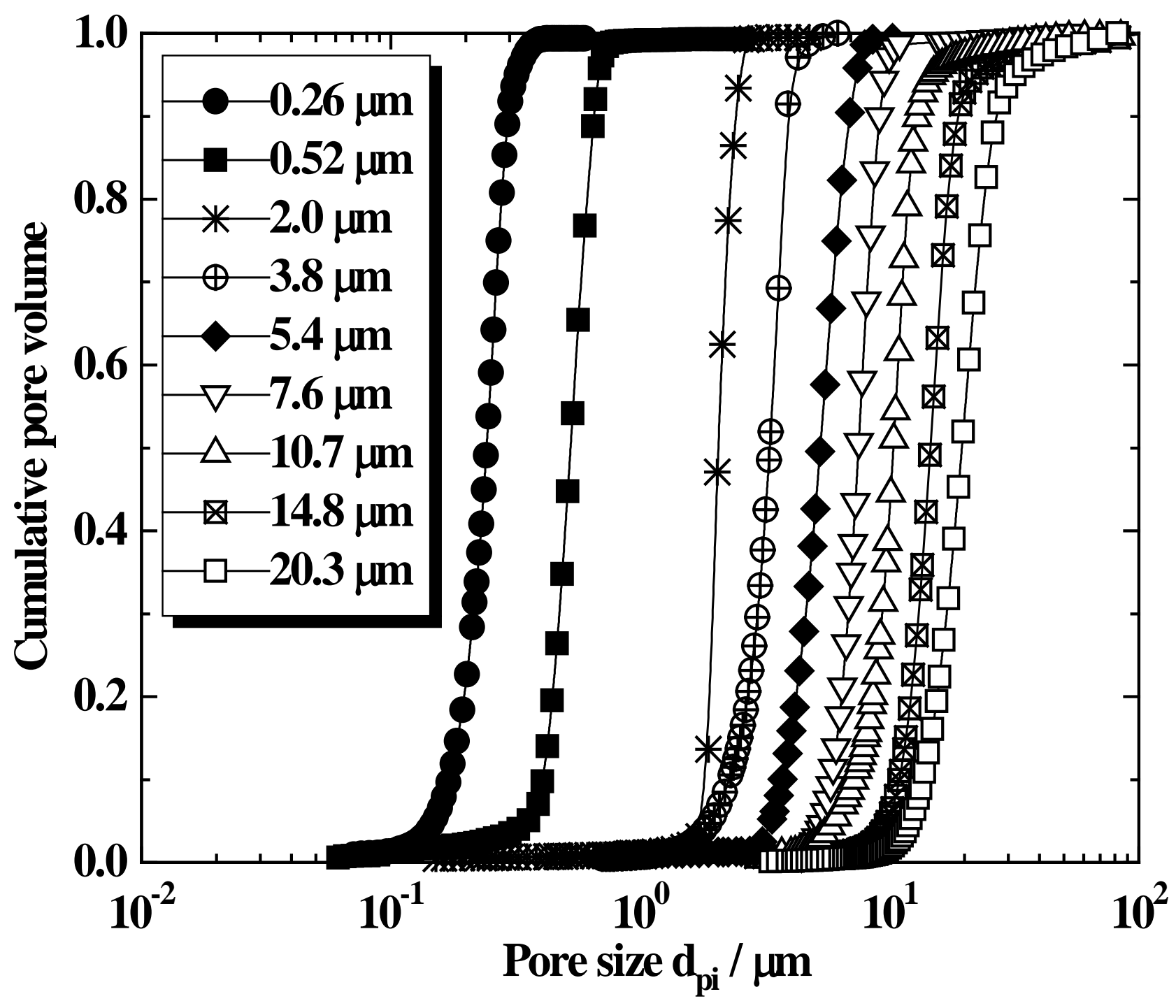

Fig. 6, Vladisavljević et al. 


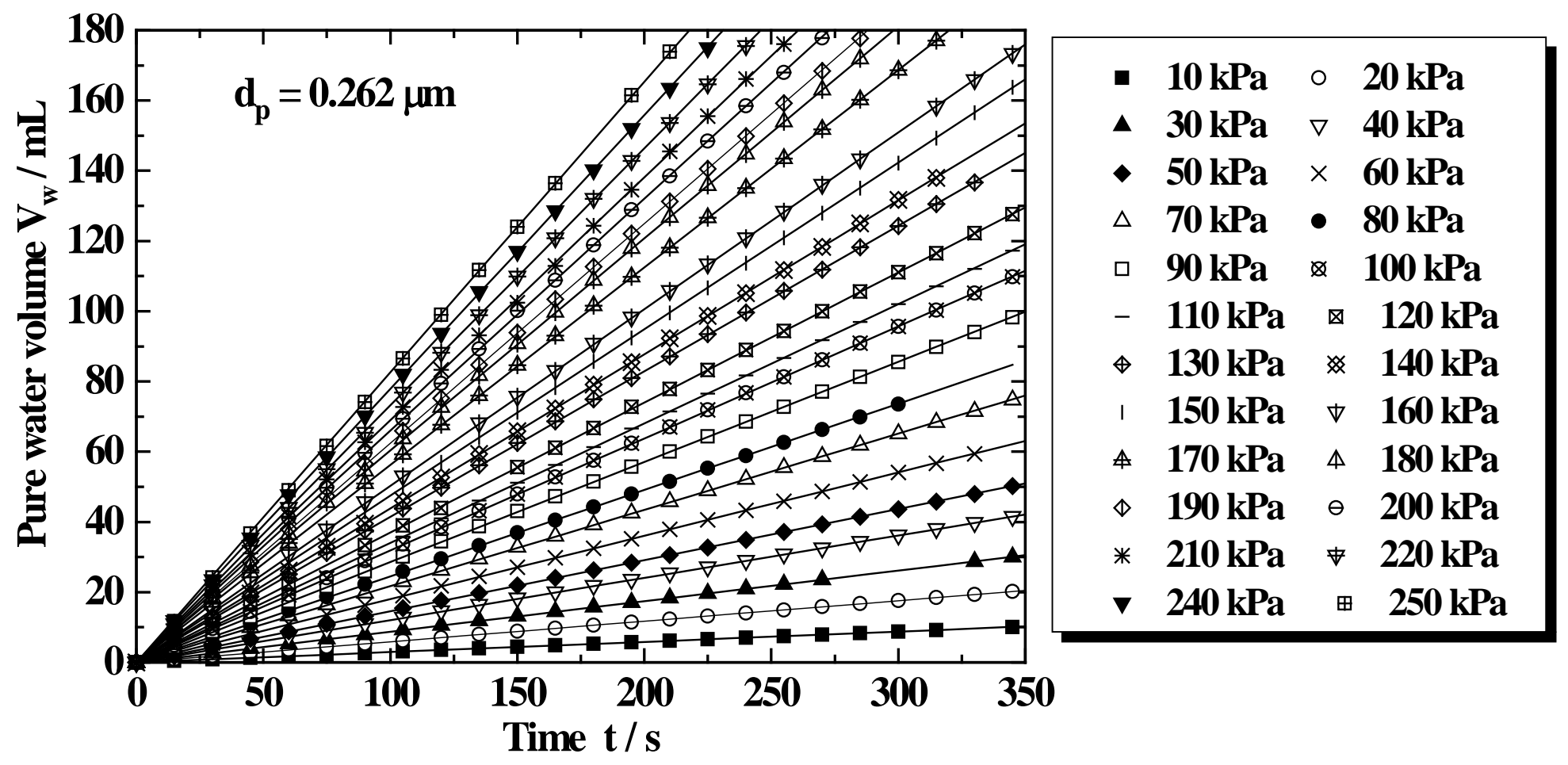

Fig. 7, Vladisavljević et al. 


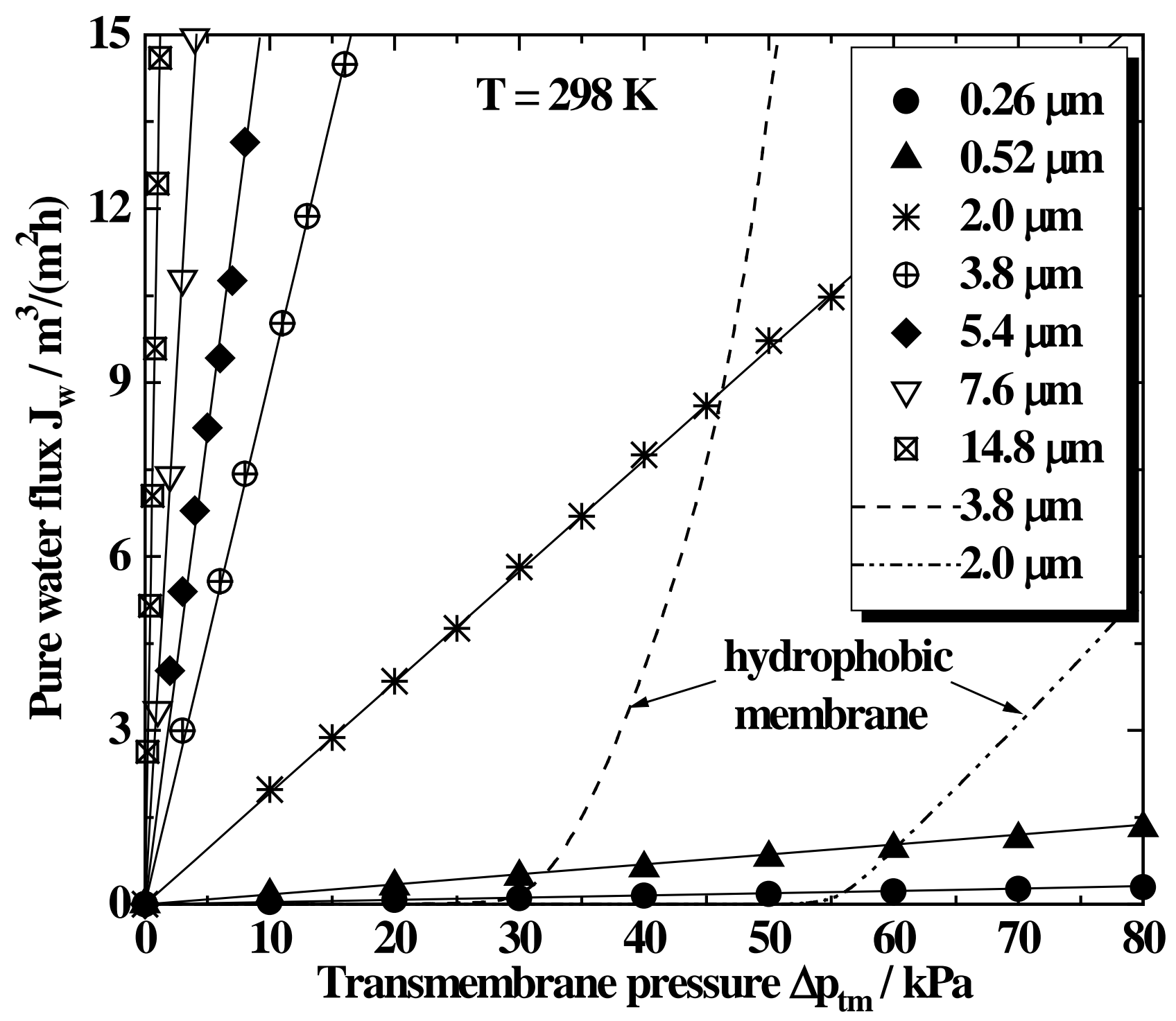

Fig. 8, Vladisavljević et al. 


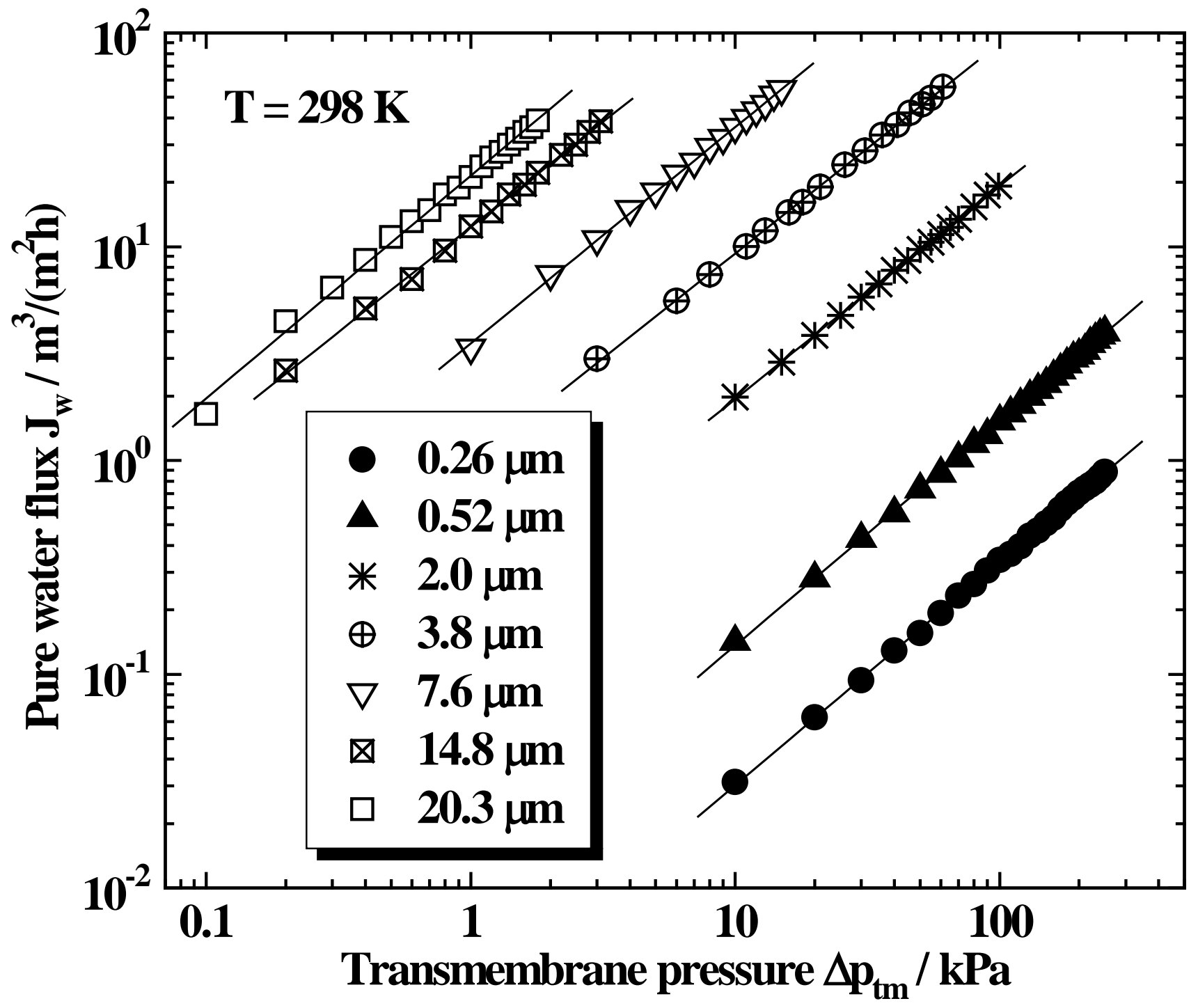

Fig. 9, Vladisavljević et al. 


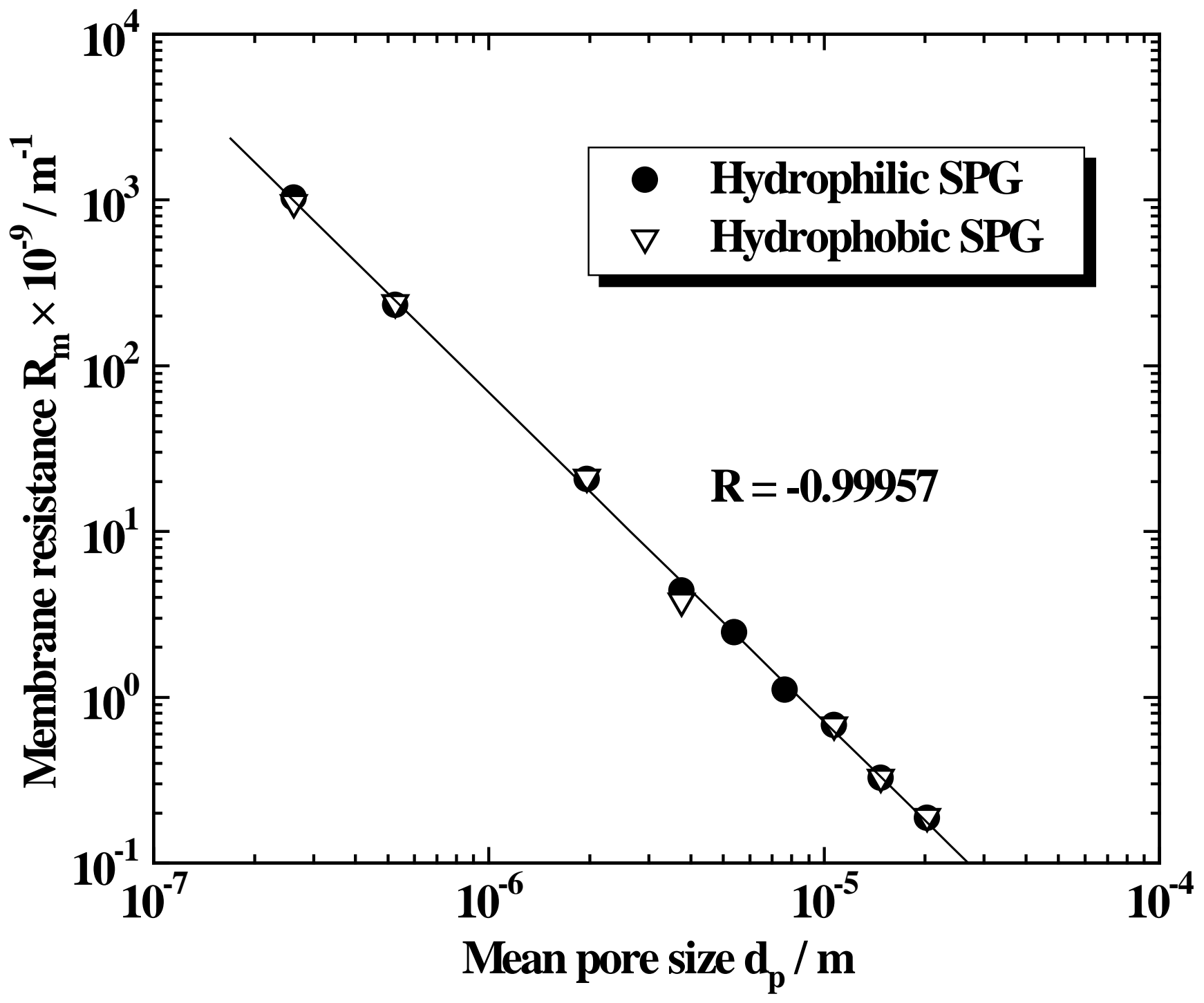

Fig. 10, Vladisavljević et al. 


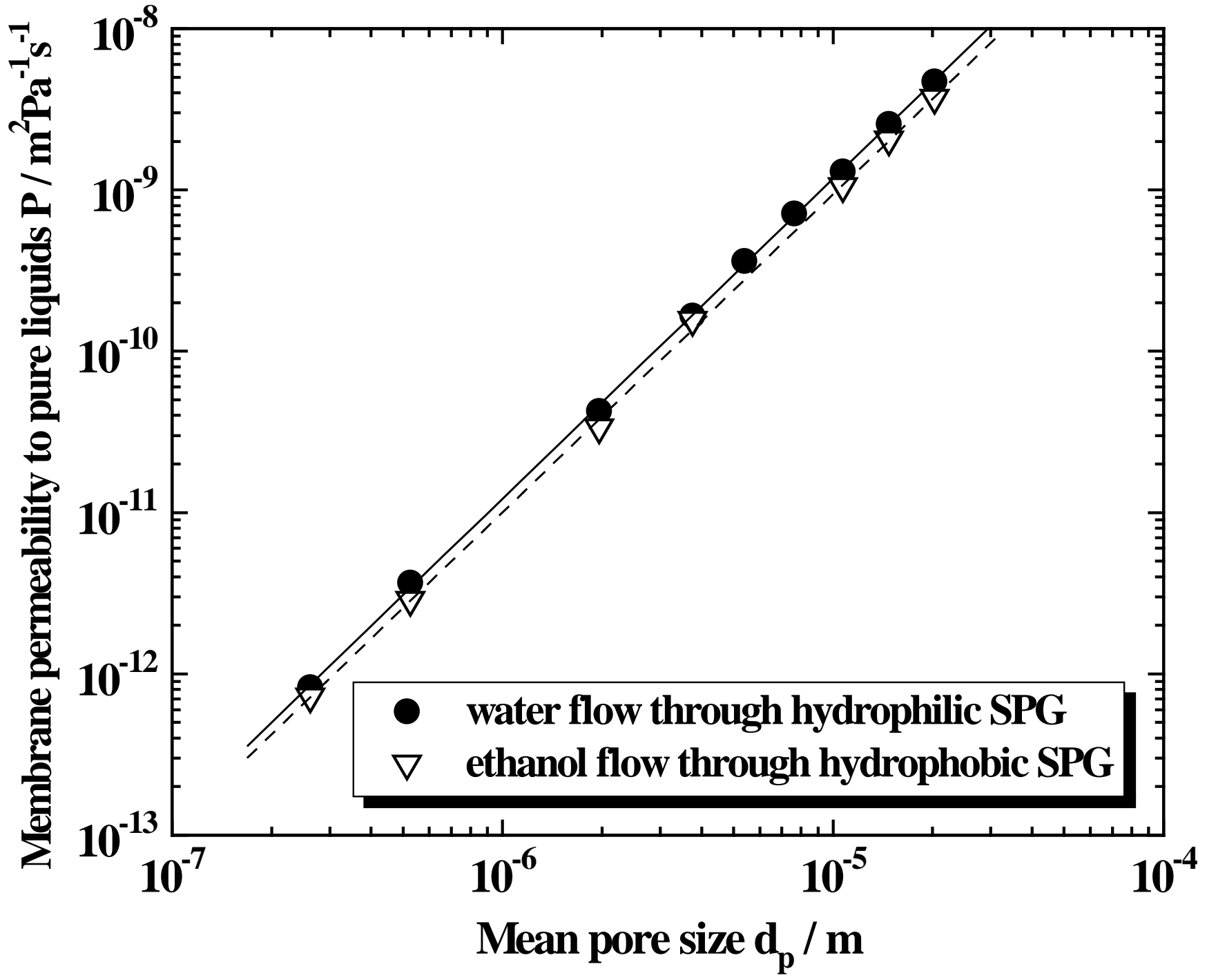

Fig. 11, Vladisavljević et al. 


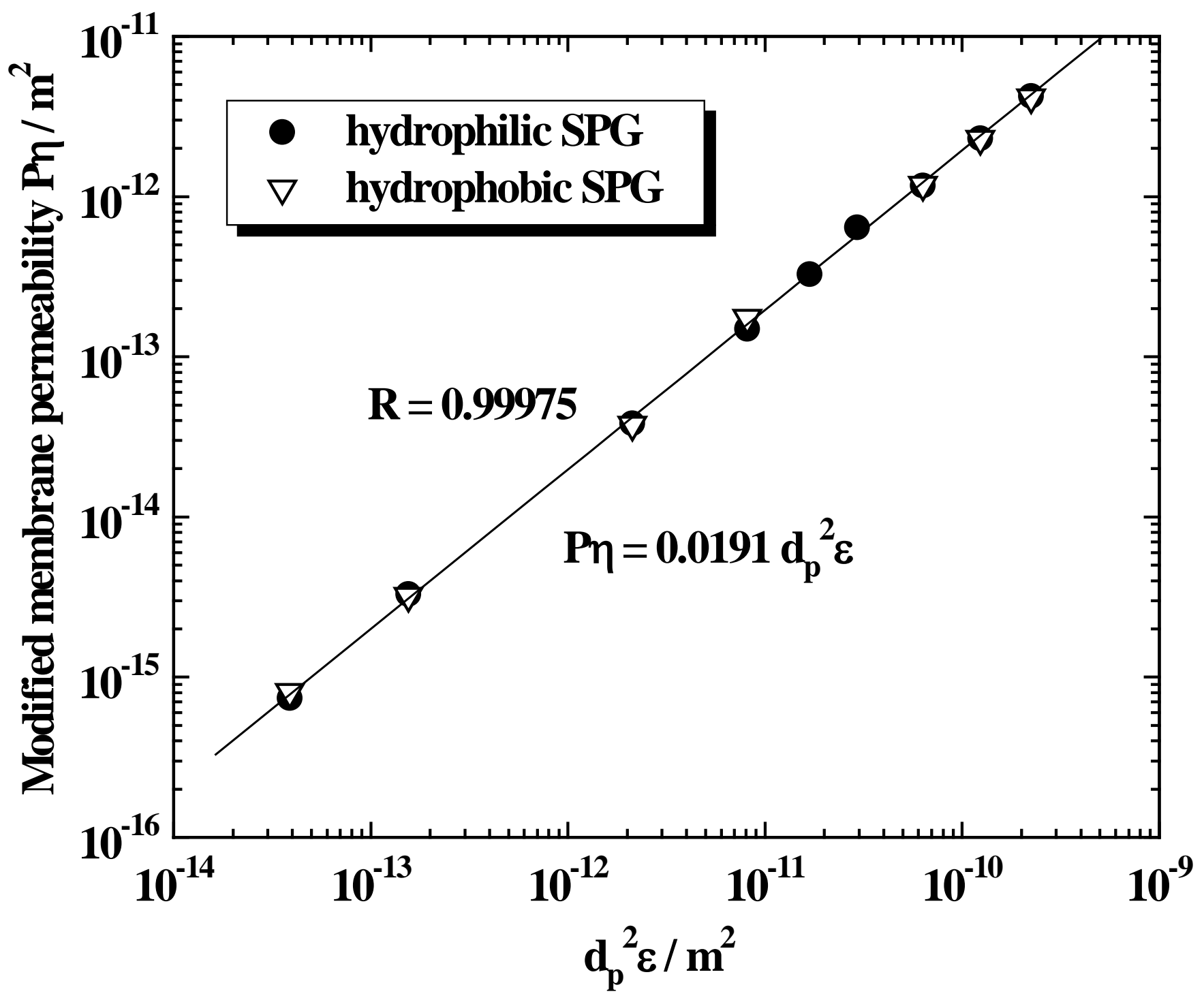

Fig. 12, Vladisavljević et al. 


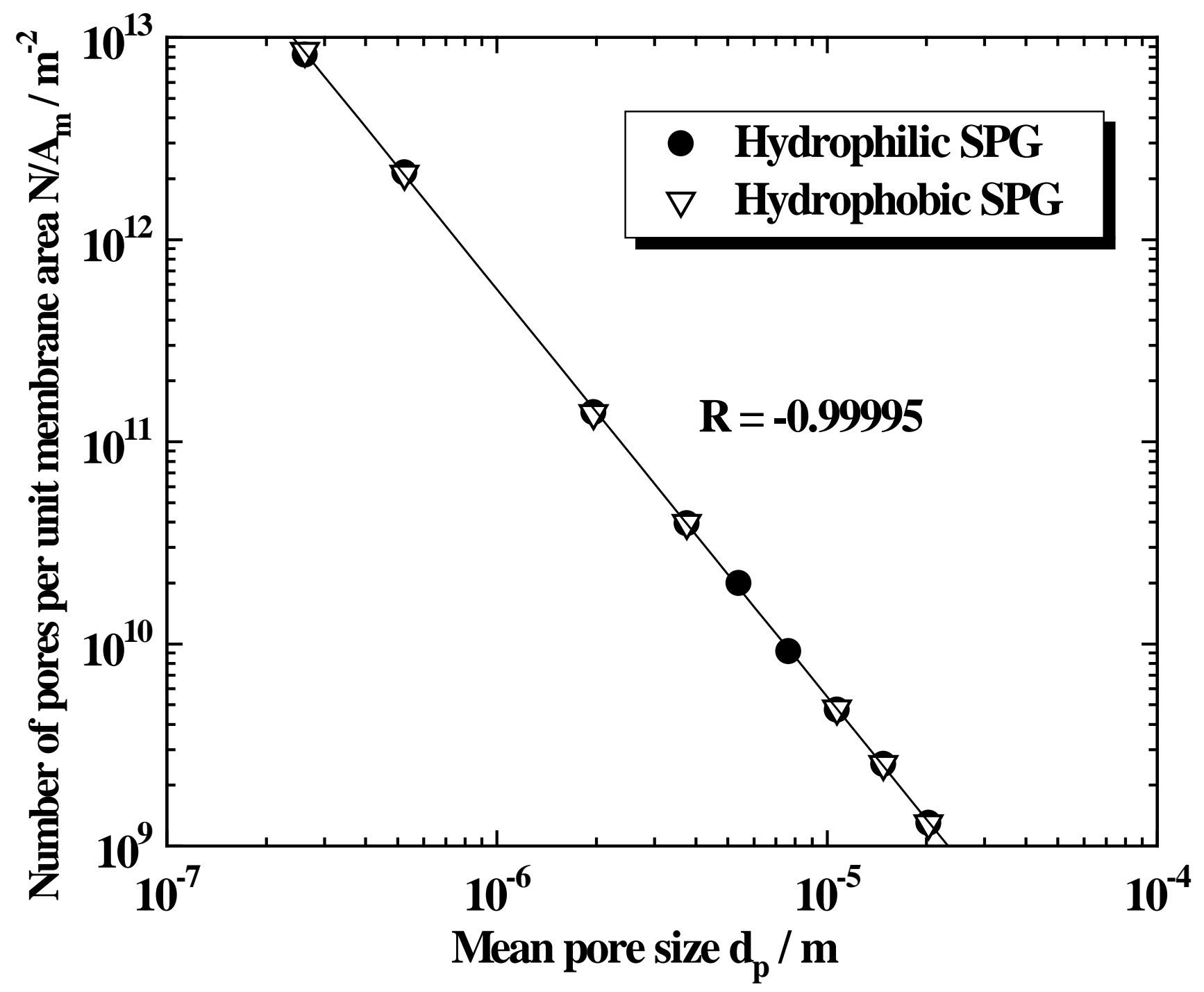

Fig. 13, Vladisavljević et al. 